review of the literature from the era of computerized tomography scanning. J Neurosurg 2000;93:940-50.

3. Hoye SJ, Hoar CS Jr, Murray JE. Extracranial meningioma presenting as a tumor of the neck. Am J Surg 1960;100:486-9.

4. Azar-Kia B, Sarwar M, Marc JA, et al. Intraosseous meningioma. Neuroradiology 1974;6:246-53.

5. Crawford TS, Kleinschmidt-DeMasters BK, Lillehei KO. Primary intraosseous meningioma: case report. J Neurosurg 1995;83:912-5

\section{Benign Lymphoepithelial Lesion of Parotid Gland and Secondary Amyloidosis as Concurrent Manifestations in Sjögren's Syndrome}

Hii-Sun Jeong ${ }^{1}$, Hye-Kyung Lee ${ }^{2}$, You-Jung $\mathrm{Ha}^{3}$, Dae-Hyun Kim ${ }^{4}$, In-Suck Suh ${ }^{1}$

${ }^{1}$ Department of Plastic and Reconstructive Surgery, Hallym University Medical Center, Halllym University College of Medicine, Seoul; ${ }^{2}$ Department of Plastic and Reconstructive Surgery, Eulji General Hospital, Eulji University School of Medicine, Seoul; ${ }^{3}$ Department of Rheumatology, Yonsei University College of Medicine, Seoul; ${ }^{4}$ Department of Plastic and Reconstructive Surgery, Myong-Ji Hospital, Goyang, Korea

Correspondence: Hii-Sun Jeong

Department of Plastic and Reconstructive Surgery, Kangnam Sacred Heart Hospital, Hallym University Medical Center, Hallym University College of Medicine, 1 Singil-ro, Yeongdeungpo-gu, Seoul 150-950, Korea

Tel: +82-2-829-5182, Fax: +82-2-829-5183

E-mail: hiisunj@gmail.com

The authors thank Sung-Eun Kim, MD and Jae-Hyun Suk, MD, for kind assistance in clinical and pathological description of this article.

This article was presented as a poster at the 70th Congress of the Korean Society of Plastic and Reconstructive Surgeons on November 9, 2012 in Seoul, Korea.

No potential conflict of interest relevant to this article was reported.

Received: 30 Mar 2014 • Revised: 24 Jun 2014 • Accepted: 25 Jun 2014 pISSN: 2234-6163• elSSN: 2234-6171

http://dx.doi.org/10.5999/aps.2015.42.3.380 • Arch Plast Surg 2015;42:380-383

Copyright (C) 2015 The Korean Society of Plastic and Reconstructive Surgeons

This is an Open Access article distributed under the terms of the Creative Commons

Attribution Non-Commercial License (http://creativecommons.org/licenses/by-nc/3.0/) which permits unrestricted non-commercial use, distribution, and reproduction in any medium, provided the original work is properly cited.

Benign lymphoepithelial lesion (BLEL) is also known as lymphoepithelial sialadenitis, lymphoepithelial lesion, myoepithelial sialadenitis, and Sjögren's-type sialadenitis. It was first reported by Johann von Mikulicz-Radecki (1888) as synchronous inflammation of lacrimal and salivary glands [1].
Sjögren then referred to it as sicca syndrome, owing to salivary gland hyposecretion [1]. Goldwin first described the lymphoepithelial changes of BLEL in major salivary glands, presenting as unilateral or bilateral glandular enlargement without clinical signs of Sjögren's syndrome [1]. However, Morgan and Castleman were the first to detail the histopathologic hallmarks of BLEL, namely marked lymphoplasmacytic infiltration with residual epimyoepithelial islands (punctuated by hyperplastic and metaplastic ducts) and acinar degeneration [1].

In amyloidosis, insoluble polymeric protein fibrils are deposited in tissues and organs extracellularly. Secondary (AA) amyloidosis is characterized by accumulation of serum amyloid protein that is triggered in the setting of chronic inflammatory or infectious disease [2].

Reported here, with a review of the literature, is a patient with BLEL and secondary amyloidosis of the parotid gland as concurrent manifestations of Sjögren's syndrome.

A 51-year-old patient arrived at our facility with a left cheek mass ( $3 \mathrm{~cm}$ in diameter), which was firm, fixed, and non-tender, although eliciting related complaints of tightness and mild pain (Fig. 1). Upon assessment of facial features, mild, bilateral enlargement of lacrimal and submandibular glands

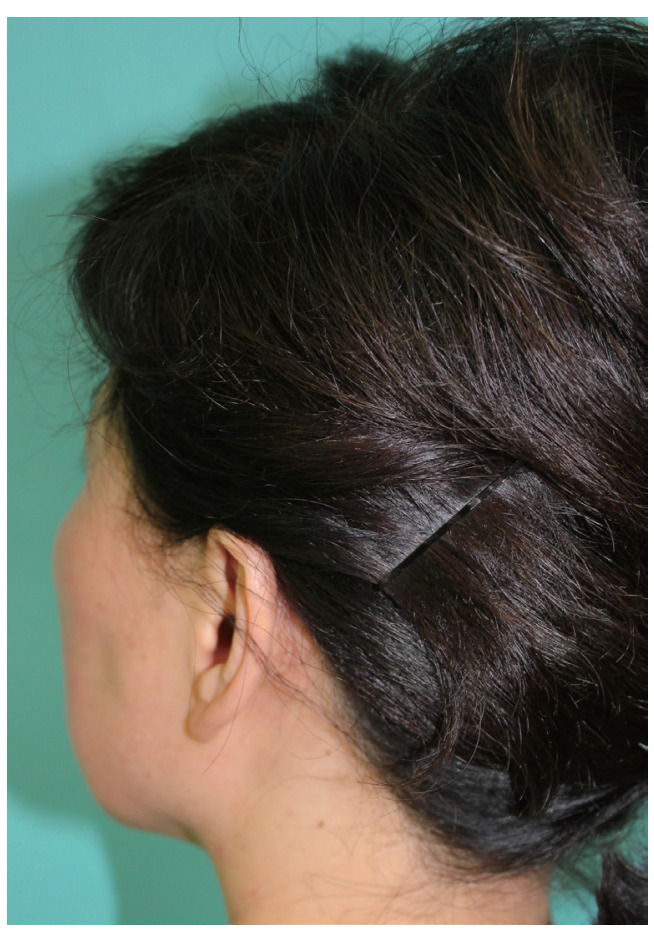

Fig. 1.

Initial appearance. 

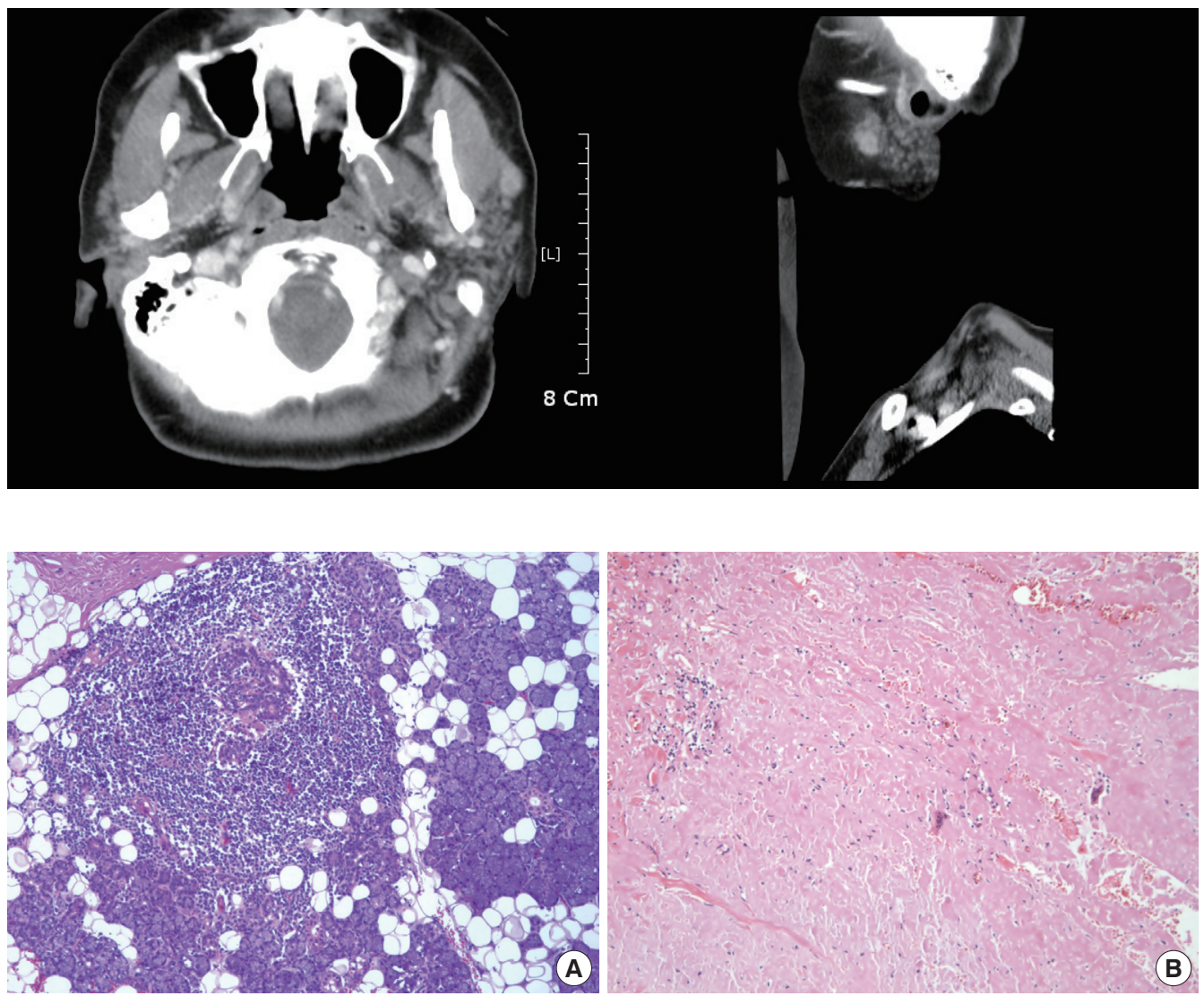

was evident, without palpable neck nodes.

Computerized tomography (CT) of the neck (with contrast) showed diffuse swelling of both parotid glands, more so on left, where another ill-defined mass was present, raising suspicion of pleomorphic adenoma or carcinoma (Fig. 2). On this basis (and considering the duration of illness), conventional superficial parotidectomy was subsequently performed. Intraoperatively, the left-sided mass was near rupture, with dense periglandular adhesions and two enlarged nearby lymph nodes. Microscopic examination showed that ductal and acinar elements were heavily infiltrated by benign lymphoid cells, and discrete germinal centers were visible, all leading to a diagnosis of BLEL (Fig. 3A). Considerable parenchymal deposition of amorphous eosinophilic material was also seen (Fig. 3B). The latter displayed the characteristic apple-green birefringence of amyloid on Congo red stain.

Due to claims of mild eye and mouth dryness in the 3 months prior to this visit, diagnostics and treatment for potential Sjögren's syndrome were initiated postoperatively. Salivary gland scintigraphy showed very low radionuclide uptake by parotid and submandibular glands bilaterally (Fig. 4). Laboratory indices were positive for rheumatoid factor, antinuclear antibody, anti-Sjörgen's-syndrome-related antigen A (anti-SSA, anti-Ro), and anti-Sjörgen'ssyndrome-related antigen B (anti-SSA, anti-La). Serum levels of immunoglobulin G (IgG) (2,220 $\mathrm{mg} / \mathrm{dL})$ and immunoglobulin A ( $\mathrm{IgA})(476 \mathrm{mg} / \mathrm{dL})$ were elevated, but immunoglobulin M (IgM) (121 $\mathrm{mg} / \mathrm{dL}$ ) and IgG4 immunoglobulin fractions (87.9 $\mathrm{mg} / \mathrm{dL}$; reference range, $39.2-894.0 \mathrm{mg} / \mathrm{dL}$ ) were within normal ranges. Results of Schirmer's test (left, $9 \mathrm{~mm}$; right, $30 \mathrm{~mm}$ ) and break-up time scores (left, $2 \mathrm{sec}$; right, $4 \mathrm{sec}$ ) were low. As suspected, the patient's profile fulfilled revised international classification criteria for Sjögren's syndrome [3].

Following surgery, the patient was given pilocarpine eye drops for treatment of dry eyes. Other than mild residual hollowing of the left cheek, she suffered no true complications during a one-year follow-up period, and she refused recommended monitoring (ultrasonography or computed tomography) to check for recurrence.

BLEL is considered an autoimmune disease of salivary glands. Clinical features of Sjögren's syndrome may be manifested by $50 \%$ to $84 \%$ of patients with BLEL, which increases the risk (40:1)
Fig. 2.

Contrast-enhanced computed tomography of neck: note bilateral diffuse swelling of parotid glands, more so on left; greater enhancement accentuates irregularly shaped 3-cm mass of left parotid gland, which proved to be amyloid.

Fig. 3.

Microscopic views (H\&E stain) of parotid gland mass: (A) obliteration of ducts and acini by benign lymphoid infiltrates forming germinal centers $(200 \times)$; (B) considerable parenchymal deposition of amorphous eosinophilic material, later confirmed as amyloid on Congo red stain $(200 \times)$. 
Fig. 4.

Scan of salivary glands: markedly diminished uptake of radionucleotide in both parotid and submandibular glands, relative to thyroid gland. AN, anterior; LT LAT, left lateral; RT, right.

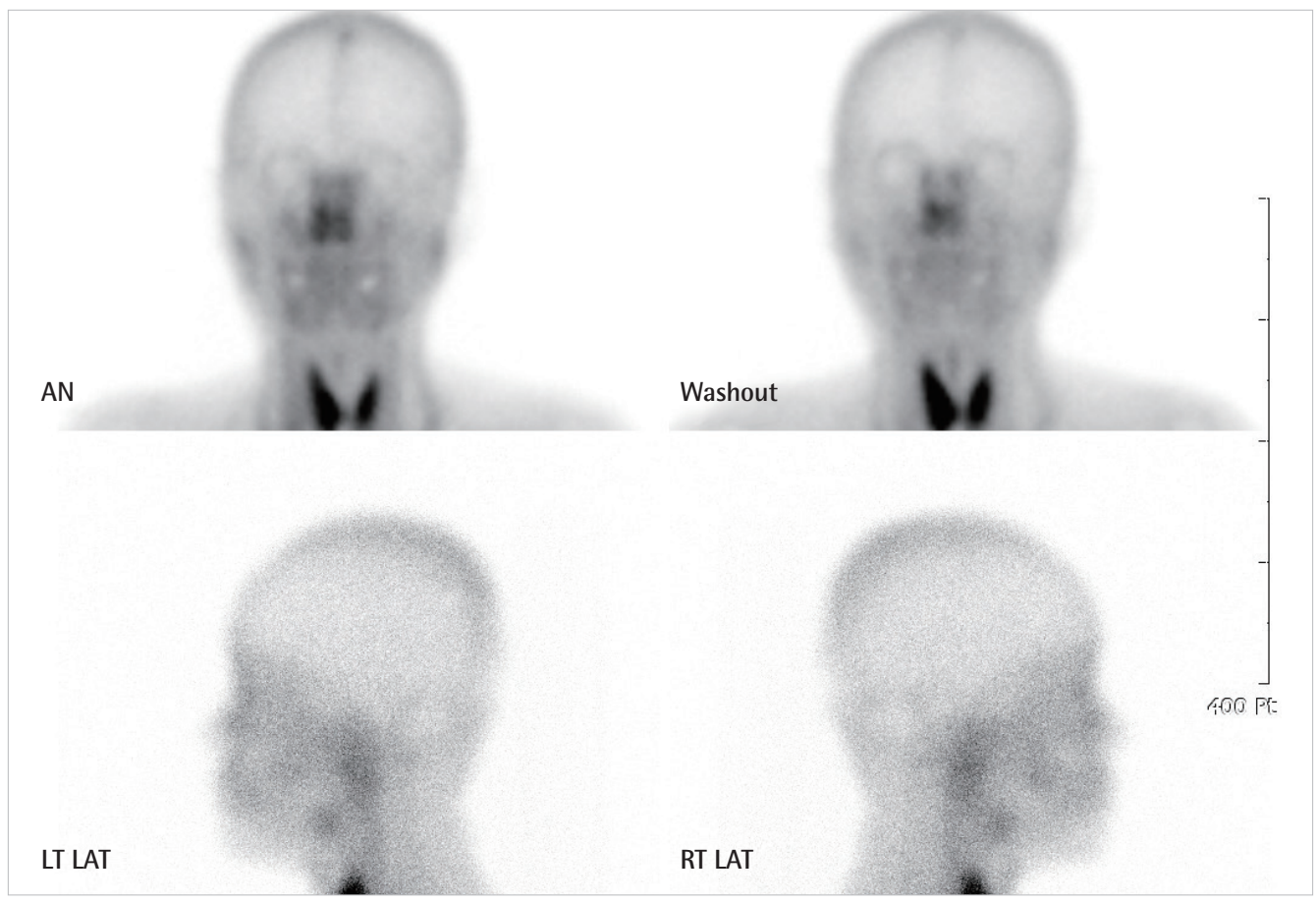

of developing malignant lymphoma, especially in long-standing BLEL. Hence, follow-up surveillance for potential malignant transformation is advised [4].

Amyloid is seen as eosinophilic fibrils in hematoxylin and eosin ( $\mathrm{H} \& \mathrm{E})$-stained tissue; and on Congo red stain, its regularly structured $\beta$-pleated sheets result in a unique apple-green birefringence under light microscopic polarization. AA amyloidosis is typically associated with chronic inflammatory disease and may be confirmed via immunohistochemistry [2].

In patients with salivary gland enlargement, diagnosis of BLEL may be difficult due to the many benign inflammatory conditions that arise and/or the occurrence of salivary cysts or tumors. For differential diagnostic purposes, imaging modalities such as CT, ultrasound, technetium scan, and sialography may be helpful, although such technical advancements are not routinely utilized in the management of salivary gland tumors. Fine needle aspiration biopsy is controversial in this setting, because for many surgeons, the presence of tumor alone is sufficient indication to operate. With a sensitivity near $90 \%$ and a specificity of $75 \%$, fine needle aspiration (FNA) biopsy may have a role in documenting the benign disease of poor-risk patients, thus avoiding inappropriate surgery [5]. Nevertheless, histologic findings may be precarious. A history of autoimmune disease or complaints of dry eyes or mouth often are diagnostic clues, given a heterogeneous lymphoid component. Grounds for diagnosis of BLEL by FNA include the presence of epimyoepithelial islands, numerous small lymphocytes, and a granular proteinaceous background [5].

Concurrent BLEL and secondary amyloidosis affecting parotid gland unilaterally have not been reported to date. In this instance, the irregularly contoured margins of accumulated amyloid and the dense periglandular adhesions observed, both induced by inflammation, are easily interpreted radiographically and grossly as signs of pleomorphic adenoma or features of malignancy. Because BLEL may be a consequence of human immunodeficiency virus infection or may progress to Hodgkin's lymphoma, history-taking is critical, and lumpectomy may be beneficial [5]. Surgical removal of such tumors is often tempting to exclude malignancy, but various radiologic modalities and/or FNA biopsy do have merit in this context, utilizing a multidisciplinary approach (i.e., rheumatologist, pathologist, and ophthalmologist) to establish a diagnosis and determine appropriate treatment. In a patient with documented autoimmune disease, the differential diagnosis of a cheek mass should include benign systemic conditions. As seen here, focal deposition of amyloid in BLEL may mimic pleomorphic adenoma or malignancy of the parotid gland. 


\section{References}

\section{Ma Q, Song H. Diagnosis and management of} lymphoepithelial lesion of the parotid gland. Rheumatol Int 2011;31:959-62.

2. Seldin DC, Skinner M. Amyloidosis. In: Ruddy S, Sledge CB, Sargent JS, et al. Kelly's textbook of rheumatology. 9th ed. Philadelphia: Elsevier; 2012. p.1889-97.

3. Vitali C, Bombardieri S, Jonsson R, et al. Classification criteria for Sjogren's syndrome: a revised version of the European criteria proposed by the American-European Consensus Group. Ann Rheum Dis 2002;61:554-8.

4. Goto TK, Shimizu M, Kobayashi I, et al. Lymphoepithelial lesion of the parotid gland. Dentomaxillofac Radiol 2002;31:198-203.

5. Chhieng DC, Cangiarella JF, Cohen JM. Fine-needle aspiration cytology of lymphoproliferative lesions involving the major salivary glands. Am J Clin Pathol 2000;113:563-71.

\section{Soft Tissue Chondroma Presenting as a Dermal Mass in the Toe}

\author{
So Min Hwang, Jang Hyuk Kim, Min Wook Kim, \\ Yong Hui Jung, Hyung Do Kim, Hong IL Kim, \\ Min Kyu Hwang \\ Aesthetic, Plastic and Reconstructive Surgery Center, Good \\ Moonhwa Hospital, Busan, Korea
}

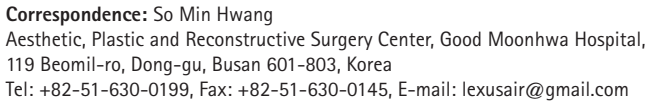

Aesthetic, Plastic and Reconstructive Surgery Center, Good Moonhwa Hospital, 119 Beomil-ro, Dong-gu, Busan 601-803, Korea

Tel: +82-51-630-0199, Fax: +82-51-630-0145, E-mail: lexusair@gmail.com

No potential conflict of interest relevant to this article was reported.

Received: 2 Aug $2014 \bullet$ Revised: 12 Sep $2014 \bullet$ Accepted: 22 Sep 2014 pISSN: 2234-6163 • elSSN: 2234-6171

http://dx.doi.org/10.5999/aps.2015.42.3.383 • Arch Plast Surg 2015;42:383-385

Copyright (C) 2015 The Korean Society of Plastic and Reconstructive Surgeons This is an Open Access article distributed under the terms of the Creative Commons Attribution Non-Commercial License (http://creativecommons.org/licenses/by-nc/3.o/) which permits unrestricted non-commercial use, distribution, and reproduction in any medium, provided the original work is properly cited.

Soft tissue chondroma is a rare benign tumor, and it mainly affects hands and feet. Its prevalence reaches the highest level in individuals aged between 30 years and 60 years. In addition, it is known that there is no sex-related difference in its incidence. Repeated microtrauma has also been reported to be responsible for its occurrence.
A 72-year-old woman visited us with a chief complaint of a 3-year-history of a palpable, skin protuberance on the left third toe. The patient had a past history of taking surgical excision for skin protuberance at the department of dermatology of other hospital. Thereafter, however, the patient received resection of the skin protuberance again because of its recurrence. Nevertheless, the patient had a palpable mass at the surgical sites and complained about discomfort in the toe. Therefore, the patient visited us. On physical examination, the patient had a round, ill-defined skin protuberance with a diameter of approximately $1 \mathrm{~cm}$. On palpation, it was a rather solid mass. In addition, the patient had a scratch on the skin surface (Fig. 1). On preoperative plain radiography, the patient had a calcified lesion with a diameter of $<1 \mathrm{~mm}$ in the deep lesion of the skin mass (Fig. 2).

After IV sedation, local anesthesia is applied and then the patient received a resection of the mass. We made an oval-shaped incision along the margin of the skin protuberance, for which we set the depth of resection at the right above the periosteum, thus attempting to sufficiently involve the subcutaneous adipose tissue. Thus, we performed a resection of the mass involving the calcified lesion identified on preoperative plain radiography. Postoperatively, the size of the resected mass was $1.0 \times 0.8 \mathrm{~cm}$. We performed histopathologic examinations (Fig. 3).

On histopathologic examinations, the patient was diagnosed with chondroma characterized by the

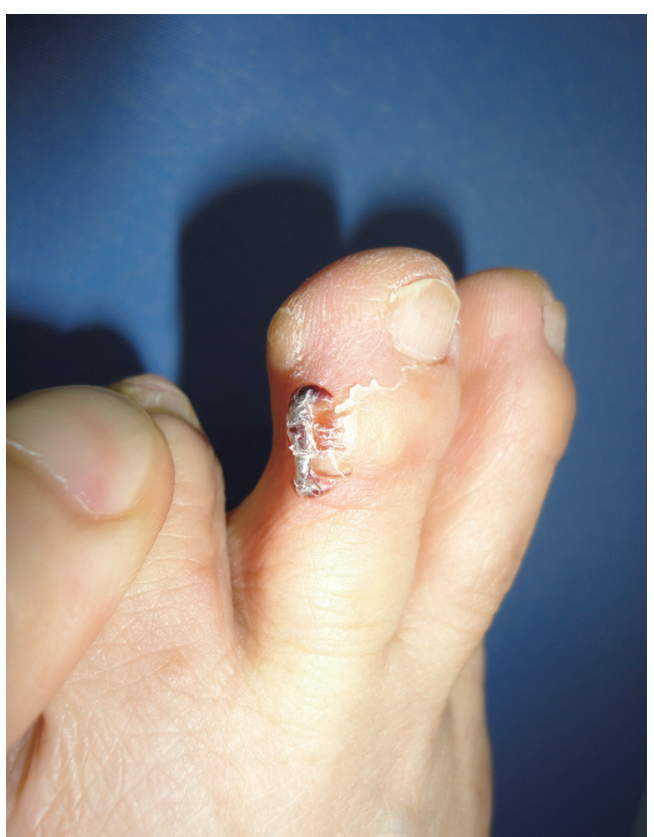

Fig. 1.

Preoperative clinical view. 72-year-old female patients visited our hospital with chief complaint of $1 \mathrm{~cm}$ sized round and protuberance skin lesion which had a indeterminated margin on dorsolateral aspect of third toe on left foot. 